\title{
EDITORIAL
}

\section{WHAT SHOULDER AND WHAT ART}

\author{
Misconceptions about how little intellectual property rights protection in China is evolving \\ could lead to missed opportunities for many companies.
}

Creating interest in China is a simple process nowadays. As Philip Stephens neatly wrote in the Financial Times ${ }^{1}$, all that is needed is a formula of "[a] rush of statistics, an occasional nod to history, a Confucian aphorism or two and, hey presto, we can all grasp the vast meaning of the Middle Kingdom's re-emergence as a global power." Unsurprisingly, using such slack-jawed observations to pique interest in China leads to grossly raised expectations and the persistence of stereotypical misconceptions.

Nowhere is this more apparent than in the pharmaceutical industry. Seductive statistics about low costs and high graduate numbers are used to promote China not only as an outsourcing centre for drug development but as a cure for industry's current productivity ills. However, standing in the way of this promise has always been intellectual property. Companies attracted to China are put off by what they believe to be a corrupt land with little respect for IP rights, and where counterfeit drugs are rife. Nearly three-quarters of the pharmaceutical executives polled for a recent Ernst \& Young survey agreed, saying that threats to IP posed a business risk in China.

Critics point to the recent Chinese court ruling that Pfizer's patent on sildenafil citrate (Viagra) is invalid as proof that IP rights protection in the country is still a nightmare. Others, however, contend that the fact that Chinese generic companies are trying to revoke the patent through the legal process rather than simply producing copycat versions of Viagra signals the emergence of a robust domestic patent system. So, what is the state of Chinas IP system?

Building an effective IP system relies on three components: the underpinning law; the quality of the rights that are acquired by the patent; and the cost and effectiveness of enforcing those rights. At a recent molecular medicine and biotechnology conference in Beijing, co-organized by Nature Publishing Group and Massachusetts General Hospital, Ian Harvey, chairman of the Intellectual Property Institute in London, said that although China introduced its first patent laws as late as the mid-1980s, its IP laws today are among the best in the world. Also, IP rights for foreign companies are generally of high quality and reasonable cost. The 20-year-lifetime cost of a Chinese patent is one-tenth of the total cost of patents for G8 countries.

The sticking point remains enforcement. China has further to go before it has a strong enforceable system, said Harvey, but the pace of change is rapid. It is possible to get a patent enforced through the Chinese court system, at a cost of up to US\$120,000 (compared with $\sim \$ 5$ million in the United States). Anecdotes about China are often repeated by people who have not themselves tried to use or enforce IP there, says Harvey. The system is not perfect, but the reality is very different from the popular perception - particularly for the pharma industry.

Driving further changes in enforcement will require China to move from domestic to global patents, and Chinese scientists to start forming international partnerships, said a panel of industry representatives at a recent New York Academy of Sciences meeting in Shanghai. The growing number of returnees with research and business experience is already fostering a healthy respect for IP. R\&D outsourcing operations in China couldn't attract the interest of multinational pharmaceutical companies if they did not manage IP well, and state-funded institutes focusing on early drug development are setting up similar frameworks in order to attract industry alliances.

Progress in China's IP system has not gone unnoticed. Roche moved where others feared to tread when it opened its $\mathrm{R} \& \mathrm{D}$ centre in Shanghai less than a year ago, and already it is beginning to patent compounds. Last month, Novartis, and perhaps most revealingly Pfizer, announced plans to open R\&D facilities in China. The desire to leap from imitation to innovation means that China is moving rapidly to set up an adequate IP system. R\&D innovation is such an important part of the Chinese government's bid to become an economic superpower that within a few years China has moved from banning to tolerating to encouraging foreign investment. Companies that continue to focus on the surface and see only an imperfect IP regime are therefore in danger of losing out on valuable opportunities by not noticing the profound changes that are occurring within.

1. Stephens, P. West blind to China's problems. Financial Times (30 June 2005). 